\title{
EN TORNO AL ORIGEN DE LA IMAGEN DEL JOVEN REBELDE: UN ANÁLISIS DE LA SOCIEDAD ESTADOUNIDENSE DESDE EL CINE
}

The Origin of The Image of The Young Rebel: An Analysis of American Society Through Cinema

Em Torno da Origem da Imagem do Jovem Rebelde: Uma Análise da Sociedade Estado-unidense através do Cinema

Daniel Mauricio Pinilla Ramírez, Universidad Externado de Colombia (Colombia) daniel-pba.9@hotmail.com

Recibido: 29 de mayo de 2019

Aprobado: 31 de enero de 2020

Fecha de prepublicación: 16 de julio de 2020 


\title{
DISERTACIONES
}

\section{ENSAYOS}

Estudios sobre imágenes en el nuevo ecosistema mediático

ISSN: $1856-9536$

Doi: https://doi.org/10.12804/revistas.urosario.edu.co/disertaciones/a.7934

Volumen 13, Número 2 / Julio-diciembre 2020

Versión PDF para imprimir desde

http://revistas.urosario.edu.co/index.php/disertaciones

\section{RESUMEN}

En la década de 1950 aparece la imagen del joven rebelde en el cine estadounidense. Este estudio se propone aportar elementos para comprender las razones de su origen y ahondar en lo que puede transmitir de la sociedad estadounidense de aquellos años. Bajo una metodología cualitativa, fueron analizadas, por un lado, una selección de películas protagonizadas por jóvenes rebeldes correspondientes a la década de 1950 y, por otro lado, una serie de artículos sobre estas realizados por críticos de cine de la época en la revista Variety y en el periódico The New York Times. A partir de una revisión histórica enfocada en los valores arraigados en la estructura social de los Estados Unidos, se eligió como categorías de análisis el individualismo y, particularmente, el protestantismo, y con base en ellas se contrastó la información primaria para rastrear continuidades o discrepancias. Mientras que algunas investigaciones rescatan el sustrato contestatario de la representación del joven rebelde en la pantalla, viendo en ellas una reivindicación juvenil, los resultados del presente estudio señalan, en cambio, un mayor influjo de los adultos, quienes imprimieron en la imagen del joven rebelde sus preocupaciones e idealizaciones respecto a sus hijos y los jóvenes en general, a la vez que la revistieron de valores tradicionales estadounidenses. El protagonismo que cobró la imagen del joven rebelde en aquella época parece responder a un contexto histórico que promovió la angustia en los adultos de aquel entonces en torno a la familia y las nuevas generaciones.

Palabras clave: juventud, familia, rebeldía, protestantismo, cine.

\begin{abstract}
In the 1950s, the image of the young rebel appeared in American cinema. This study thus offers the elements to understand the reasons for its origin and delve into what it can convey about American society in the given period. By using a qualitative methodology, first, a selection of films starring young rebels from the 1950s and, second, a series of articles on these films by critics from that period in Variety magazine and The New York Times were analyzed. Employing a historical review focused on the values rooted in the social structure of the United States, individualism and, particularly, Protestantism were selected as analysis categories. Based on them, the primary information was contrasted to track continuities or discrepancies. While some research studies reclaim the contentious substratum of the representation of the young rebel in films, seeing in them a vindication of youth, the results of this study indicate a greater influx of adults instead who branded the image of the young rebel with their concerns and idealizations regarding their children and youth in general and clothed this image with traditional American values. The leading role that the image of the young rebel played at that time seems to respond to a historical context that promoted the anguish in adults during that period regarding American families and the new generations.
\end{abstract}

Keywords: Youth, cinema, family, rebel, protestantism. 


\section{RESUMO}

Na década de 1950 aparece a imagem do jovem rebelde no cinema estado-unidense. Este estudo propõe-se aportar elementos para compreender os motivos de sua origem e aprofundar no que pode transmitir da sociedade estado-unidense daqueles anos. Sob uma metodologia qualitativa, foram analisadas, por um lado, uma seleção de filmes protagonizadas por jovens rebeldes correspondentes à década de 1950 e, por outro lado, uma série de artigos sobre estas realizados por críticos de cinema da época na revista Variety e no jornal The New York Times. A partir de uma revisão histórica enfocada nos valores arraigados na estrutura social dos Estados Unidos, se elege como categorias de análise o individualismo e, particularmente, o protestantismo, e com base nelas se contrastou a informação primária para rastrear continuidades ou discrepâncias. Enquanto algumas pesquisas resgatam o substrato contestatário da representação do jovem rebelde no ecrã, vendo nelas uma reivindicação juvenil, os resultados do presente estudo assinalam, por outro lado, um maior influxo dos adultos, quem imprimiram na imagem do jovem rebelde suas preocupações e idealizações respeito aos seus filhos e aos jovens em geral, ao mesmo tempo que a revestiram de valores tradicionais estado-unidenses. O protagonismo que tomou a imagem do jovem rebelde naquela época parece responder a um contexto histórico que promoveu a angústia nos adultos daquela época sobre a família e as novas gerações.

Palavras chave: Juventude, Família, Rebeldia, Protestantismo, Cinema.

En los Estados Unidos, durante la década de 1950, aparece el joven rebelde en la gran pantalla, erigiendo una imagen que aún hoy permanece en los medios. Este trabajo se propone aportar elementos para comprender las razones de su origen y ahondar en lo que puede trasmitir de la sociedad que la vio nacer: el pueblo estadounidense de mediados del siglo xx.

En un constante diálogo con el contexto histórico, fueron analizadas de manera cualitativa las principales producciones cinematográficas de la década de 1950 en las que fue representado el joven rebelde, por un lado, y los medios impresos que se encargaron de reseñarlas, por otro.

Mediante un enfoque diferente al de los autores que analizaron este tipo de películas, este artículo busca hallar los puntos de conexión entre estas y los valores tradicionales estadounidenses fuertemente arraigados a su estructura social, enfocándose principalmente en aquellos que derivaron del protestantismo. Todo con el fin de responder, desde un punto de vista sociológico, a la pregunta de por qué en esta época la juventud dejó de ser un elemento pasivo en el cine y pasó a ocupar una posición central.

Algunos elementos fueron determinantes en este proceso: la idealización e individualización de la juventud y la angustia por preservar la familia, los valores tradicionales y, particularmente, la posición que las generaciones venideras iban a ocupar en medio de ellos. En este sentido, se postula la tesis de que la imagen del joven rebelde 


\section{DISERTACIONES}

ENSAYOS

Estudios sobre imágenes en el nuevo ecosistema mediático

ISSN: $1856-9536$

Doi: https://doi.org/10.12804/revistas.urosario.edu.co/disertaciones/a.7934

Volumen 13, Número 2 / Julio-diciembre 2020

Versión PDF para imprimir desde

http://revistas.urosario.edu.co/index.php/disertaciones

trasmitida en las películas de esta época fue un medio en el que se expresó, por un lado, la preocupación hacia ese grupo etario y, por otro, se le revistió de valores que iban en sintonía con la estructura valorativa tradicional estadounidense, satisfaciendo así los deseos inconscientes de la población adulta, principal responsable de la imagen cinematográfica del joven rebelde.

\section{Antecedentes del estudio del joven rebelde de Hollywood}

La academia ha realizado interpretaciones del joven rebelde en el cine que van desde la década siguiente al estreno de los filmes hasta el presente siglo. Numerosos trabajos (Turner, 1987; Morin, 1966; Lipovetsky \& Serroy, 2009; Dinerstein \& Goodyear, 2014) indicaron que las películas del joven rebelde, en las que destacan los personajes interpretados por Marlon Brando y James Dean, contenían las demandas, los dramas y la óptica del naciente grupo de edad adolescente, en su esfuerzo por hacerse de un espacio en la estructura social. Este nuevo tipo de cine, según Gilles Lipovetsky y Jean Serroy (2009), da cuenta de la modernidad vanguardista:

Con una efervescencia creadora no exenta de radicalismo, este cine de ruptura impone la juventud como valor mediante figuras representativas de un género nuevo - James Dean, Marlon Brando, Jean-Paul Belmondo-y películas que reflejan formas de rebeldía que aspiran a liberarse de las viejas ataduras [...]. Entre comienzos de los años cincuenta y la explosión contestataria de los sesenta, sin olvidar la libertad creativa del renacido Hollywood de los setenta, hay un solo movimiento de emancipación artística y cultural, que se consolida y crece con películas y universos imaginarios muy distintos. Es inseparable de una nueva modernidad individualista, la que traen la sociedad de consumo, sus valores y sus enemigos: felicidad, sexualidad, juventud, autenticidad, placeres, libertad, rechazo de las normas convencionales y rigoristas (Lipovetsky \& Serroy, 2009, p. 20).

Para Edgar Morin (1966), la cultura de masas presenció el ascenso del joven en el mundo social. De la mano del rock de Elvis Presley y de los nuevos contenidos del cine, la década de 1950 visibilizó el despegue de la juventud como grupo de edad. Conforme esta avanzaba, se iba arrinconando a la vejez dentro de la jerarquía social. Este desplazamiento también afectó a los padres, quienes, según él, cedieron espacio en la gran pantalla, siendo muchas veces invisibilizados en el cine estadounidense. No obstante, agrega, hay películas como East of Eden o Rebel Without a Cause, donde tienen una aparición marginal y se les muestra como padres derrotados. Adrian Turner (1987), en una línea similar a los autores mencionados, sostiene que aquel cine arremetió contra los tabúes de la sociedad estadounidense, y que todas las películas de Dean cometieron un ataque a la autoridad y la influencia paterna.

Morin (1966) cree que las películas de Dean, junto con la icónica The Wild One, trasmiten un sentimiento de tragedia propio de la adolescencia. Siguiendo los planteamientos de Morin, parece que James Dean fuera el delegado para llevar a cuestas la imagen de la juventud de los años cincuenta. Es la misma opinión de George Sadoul (1989) cuando habla de Nicholas Ray y "su famoso Rebel without a Cause, uno de los films que mejor expresaron la inquietud de la adolescencia norteamericana. Este film fijó, bajo los rasgos de James Dean, el tipo de la generación salvaje" (p. 332). Una frase de Joel Dinerstein y Frank Goodyear resume esta idea: 


\section{DISERTACIONES}

ENSAYOS

Estudios sobre imágenes en el nuevo ecosistema mediático

ISSN: $1856-9536$

Doi: https://doi.org/10.12804/revistas.urosario.edu.co/disertaciones/a.7934

Volumen 13, Número 2 / Julio-diciembre 2020

Versión PDF para imprimir desde

http://revistas.urosario.edu.co/index.php/disertaciones

When James Dean first appeared on-screen in East of Eden (1955), he was the first teenager to fill the big screen with all the attendant tensions of adolescence. American teenagers of the mid1950s flocked to see themselves represented in his tormented yearnings, his romantic brooding, his attempts to do the right thing (Dinerstein \& Goodyear, 2014, p. 11).

Los trabajos citados tienen en común, además de hacer clara referencia a la rebeldía, el interpretar las representaciones del joven rebelde como un indicio de los cambios culturales que ocurrirían en los años siguientes. Este enfoque sugiere que las películas anticipan la lucha contra elementos tradicionales de la sociedad. Lejos de querer desvirtuar dichos aportes, este artículo propone un cambio de perspectiva, según la cual la imagen del joven rebelde recoge valores y nociones que desde antaño hacen parte de la estructura social estadounidense. Esto, a su vez, conlleva a fijar la vista en otra población. Ya no serán los adolescentes el grupo de edad privilegiado en el análisis, sino los adultos.

\section{El rebelde, ¿una construcción adulta?}

\section{Motivos que dirigieron la atención hacia la juventud}

Este apartado expondrá argumentos que señalan la mayor influencia de los adultos en la construcción de la imagen del joven rebelde del cine y apuntan a que esta población era la más interesada, conscientemente o no, en representar a esta nueva generación. Si bien fueron películas con temáticas juveniles, no hay contradicción en que una imagen creada a partir de la percepción y los deseos adultos hubiese agradado a los espectadores adolescentes.

Los argumentos aquí contemplados serán la idealización e individualización de la juventud y las angustias en torno a esta. Todos incidieron en la manera en que los adultos miraron a los jóvenes y se interesaron por ellos. Los argumentos, a su vez, se sustentan en la premisa de que toda creación cultural parte de la experiencia de los creadores. En el caso de las películas, los responsables directos fueron adultos (la mayoría de directores superaban los 45 años al momento de su estreno), grupo de edad que compartía una imagen hasta cierto punto generalizada de los jóvenes de su sociedad.

En cuanto a los motivos de angustia, el más global fue quizás la Guerra Fría y la incertidumbre que generó. De ahí se derivó el miedo al enemigo interno y a las ideologías ajenas a las tradicionales (Fontana, 2011). Este último punto encuentra relación con el nacimiento de la Generación Beat, que no se limitó al movimiento de un grupo de escritores, sino que constituyó un modelo a seguir para muchos jóvenes que se oponían al consumismo, a las religiones dominantes y en general a muchos valores que caracterizaban al trabajador industrial y a la familia tradicional (Goodman, 1971; Huddleston, 2012; Rubio Lapaz \& Kanelliadou, 2009). Dichos fenómenos, de la mano del aumento de las pandillas juveniles, pudieron suscitar la preocupación en torno a los jóvenes.

Con el fortalecimiento de los aparatos mediáticos, la publicidad y el auge de una clase media que proveyó a sus hijos de mayor poder adquisitivo, los jóvenes, más precisamente los adolescentes (concepto nacido a mitad de siglo), cobraron más importancia como grupo de edad, y con ello incrementó su idealización y la correspondiente tendencia de los adultos a imitar sus pautas; lo que a su vez fue una estrategia para no perder la influencia sobre sus hijos (Parsons, 1967; Gonzáles-Anleo, 2014). 


\section{DISERTACIONES}

ENSAYOS

Estudios sobre imágenes en el nuevo ecosistema mediático

ISSN: $1856-9536$

Doi: https://doi.org/10.12804/revistas.urosario.edu.co/disertaciones/a.7934

Volumen 13, Número 2 / Julio-diciembre 2020

Versión PDF para imprimir desde

http://revistas.urosario.edu.co/index.php/disertaciones

Por ese entonces, la familia y la crianza de los hijos crecieron en importancia, en parte motivados por algunos fenómenos arriba enunciados y por la Segunda Guerra mundial, cuyos estragos intensificaron la valorización de las familias y el cuidado de sus miembros (Brinkley, 1996). En relación con esto, Davis Riesman (1971) relata que no solo la disminución del número de hijos produjo que los padres modernos concentraran más sus energías en su más escasa descendencia, sino también el cambio en las funciones de los hijos dentro del hogar: dejaron de participar en actividades dedicadas a la economía familiar, eliminando, principalmente en la clase media, el papel de los hijos como mano de obra familiar. De ambas trasformaciones devino un aumento en la importancia de la crianza y un correspondiente incremento en la preocupación hacia los hijos, Hareven coincide con Riesman y agrega que como resultado de tal proceso se dio una mayor individualización de los niños a los ojos de los padres, quienes centraban en ellos su atención (Hareven, 1990).

El cine logró captar esta individualización mediante la utilización, consciente o no, de recursos propios de su lenguaje, como la representación del hijo único, característica de películas como Rebel Without a Cause o Never love a Stranger. No obstante, dos recursos fueron más significativos. El primero fue la oposición ante un personaje contrario en cuanto a su relación con la autoridad, generalmente un hermano. La relación entre Cal y Aron de East of Eden es quizás la muestra más clara. El segundo fueron las situaciones de riesgo: estrategia cinematográfica donde se pone en peligro la vida de un personaje, habitualmente protagónico, consiguiendo destacarlo frente a personajes menos primarios. Y este último recurso involucra un elemento todavía más interesante. Mientras que para otros tipos de aventureros de la gran pantalla la principal amenaza es externa, principalmente de carácter física, los jóvenes rebeldes deben soportar, además, la amenaza interna. Así pues, los padres de Jimmy, de Cal o de Barbella parecen angustiarse, además de los peligros que representan los demás individuos o el ambiente mismo, por la interioridad de su hijo. Es una doble dimensión de riesgo que involucra el miedo a que pierda la vida y a que deteriore su alma o no logre corregirla. Ambos son potencialidades de la desviación.

\section{La rebeldía: una amenaza percibida en la familia}

El cine de ficción, afirma Marc Ferro, ofrece un espacio para las críticas, sobre las cuales se puede reflexionar en la relación de los filmes con la sociedad (Ferro, 1980). Jesús Martín-Barbero (2010), apoyado en su concepto de mediaciones, afirma que los medios masivos de comunicación, principalmente los que se apoyaron en herramientas publicitarias, introdujeron en sus productos valores e intereses propios de lo popular. Siguiendo a este autor, los mensajes masivos destinados al pueblo incluyen sus experiencias, intereses y valores; compartidos también por los mismos encargados de elaborar y difundir dichos mensajes. Con base en esta perspectiva teórica, se llevó a cabo un análisis de contenido bajo un método cualitativo. Allí se analizaron las opiniones de algunos críticos de cine que escribieron en el diario The New York Times y la revista Variety. Sus artículos son contemporáneos a las películas tratadas, de manera que se los abordó como información primaria desde la cual se puede acceder a la mirada del pueblo estadounidense. Para el caso de las películas, el análisis se sirvió de la identificación de actores, de sus relaciones dentro de instituciones, como la familia, y relaciones de autoridad entre ellos, para así establecer un marco que permitiese la lectura de los desafíos a la autoridad y a las normas sociales dentro del lenguaje narrativo. 


\section{DISERTACIONES}

ENSAYOS

Estudios sobre imágenes en el nuevo ecosistema mediático

ISSN: $1856-9536$

Doi: https://doi.org/10.12804/revistas.urosario.edu.co/disertaciones/a.7934

Volumen 13, Número 2 / Julio-diciembre 2020

Versión PDF para imprimir desde

http://revistas.urosario.edu.co/index.php/disertaciones

Bosley Crowther, crítico de cine del The New York Times, se refiere a los jóvenes representados en las películas como si se tratara de personajes dignos de aterrorizar al público. De Rebel Without a Cause destaca el potencial mortal de estos, resaltando el porte de navajas y la habilidad en su manejo. Además, se refiere al grupo de jóvenes como delincuentes, señalando las prendas que usan ("villainous schoolboys in black-leather jackets and cowboy boots") como refuerzo visual de tal imagen (Crowther, 1955). Robert Landry (1955) centra su atención sobre los mismos aspectos. Para él, la delincuencia es un aspecto principal de Rebel Without a Cause, notando también el uso de navajas por parte de los jóvenes. Ambos autores consideran evidente la relación entre la temática de esta película y Blackboar Jungle, estrenada el mismo año. Para ellos, los puntos de unión están en la impactante imagen de estudiantes en un ambiente de bullying, cuyas actividades de ocio son inapropiadas, sus comportamientos sádicos y donde son propensos a hacer uso de navajas como instrumento (Landry, 1955; Crowther, 1955). Una frase de Crowther sobre Rebel Without Cause es ilustrativa al respecto: "It is a violent, brutal and disturbing picture of modern teen-agers that Warner Brothers presents in its new melodrama at the Astor".

En 1953 se estrenó The Wild One, película que generó similar impacto en los críticos de cine. De nuevo, Crowther (1953) describe en ella a una juventud vandálica que plasma una perspectiva libertina de los jóvenes modernos. Habla de unos jóvenes amenazantes que no tienen respeto por la autoridad policiaca ni por la población decente (Crowther, 1953). En su reseña explicita la diferenciación entre los ciudadanos del común y los rebeldes; diferenciación que será esencial para el análisis sociológico de los contenidos fílmicos. La película se encarga de asegurar la visibilización de ese antagonismo, también destacado en la reseña hecha por Variety (1952), aun antes del estreno.

En la descripción de Crowther sobre The Wild One, se etiqueta a estos jóvenes como amenazantes, adjetivo que cobra más sentido en oposición a los llamados "ciudadanos del común". También se los señala, en ambos medios, como imprudentes, seguramente en relación con lo que Crowther define como su búsqueda de sensaciones, particularmente de sensaciones producidas al desafiar a la sociedad normal. A Johnny, interpretado por Marlon Brando, lo describe como un cruel matón, y a Chino, otro joven rebelde, como un psicópata o posible drogadicto: "there is briefly injected into this picture a glimpse of utter monstrosity, loose and enjoying the privilege of hectoring others in a fair society" (Crowther, 1953).

Blackboard Jungle, definida por Crowther (1955) como una película que narra una historia de maldad desenfrenada "and criminality among the students in a large city vocational training school", sitúa a los jóvenes urbanos como los protagonistas. Todas las reseñas tratadas hasta ahora hacen referencia explícita a los jóvenes modernos:

"[...] brutal and disturbing picture of modern teen-agers", "[...] menacing element of modern youth" (Crowther, 1953). "'Rebel without a Cause' cannot escape comparison with Metro's recent 'Blackboard Jungle.' Each film depicts modern highschool student bodies as ruled by sadistic" (Landry, 1955). "More than a question of entertainment is involved, however, in this film, since it treats of a contemporary subject that is social dynamite" (Crowther, 1955).

Pero esta nueva precisión, de "jóvenes urbanos" especifica más la conexión entre la representación y el fenómeno que le había dado vida (las pandillas juveniles urbanas).

Los rasgos destacados por los escritores no nacieron de forma espontánea, sino de un auténtico temor hacia la brutalidad de los grupos de jóvenes y, seguramente, por la generalización de comportamientos rebeldes en los adolescentes, como comunican Parsons (1967) o Goodman (1971). En algunos casos, la relación con el mundo 


\section{DISERTACIONES}

ENSAYOS

Estudios sobre imágenes en el nuevo ecosistema mediático

ISSN: $1856-9536$

Doi: https://doi.org/10.12804/revistas.urosario.edu.co/disertaciones/a.7934

Volumen 13, Número 2 / Julio-diciembre 2020

Versión PDF para imprimir desde

http://revistas.urosario.edu.co/index.php/disertaciones

empírico es todavía más cercana, como aquel suceso de motociclistas que aterrorizaron a una comunidad en California y que inspiró la a película The Wild One (Variety, 1952).

Somebody Up There Likes Me retrata la juventud del boxeador Barbella, descrito por Crowther (1956) como " $a$ picture of a mean, rebellious kid" que no tiene control de sí mismo. Se refiere a él como un matón que transitó por uno y otro establecimiento carcelario y exploró varias formas de robo. Barbella es representado como un joven que debe lidiar con un padre alcohólico y maltratador y con las consecuencias de llevar una vida de desafíos a las normas sociales.

East of Eden está basada en un libro de John Steinbeck con el mismo nombre, publicado tres años antes que el filme. Crowther (1955) llama la atención sobre el hecho de que solo una reducida parte del libro haya sido elegida por Kazan para llevar a cabo la producción: la parte que abarca la relación de tensión entre un hijo consternado y con dilemas morales sobre sí mismo y su padre, un religioso que procura encaminarlo a que se comporte como su hermano, quien ejemplifica al hijo obediente y ceñido a la autoridad paterna. Sin olvidar a su madre, mujer que reniega de la religión y cuya ausencia incide en los problemas de Cal.

La rebeldía se expresa mediante algún tipo de desafío. Para el caso de las representaciones cinematográficas consideradas, tal desafío recae en gran medida sobre el orden establecido en la familia tradicional estadounidense o, por lo menos, de la idealización que de ella se tenía. De una u otra forma, las narraciones se desarrollan en torno a una situación familiar problemática.

En los artículos se destacan los conflictos entre hijos y padres y, en no pocos casos, se les considera la causa primera de la conducta rebelde de los jóvenes representados. Crowther (1955) menciona en su artículo que el guionista de Rebel Without a Cause, Stewart Stern, informa que la personalidad de Jimmy es el resultado de la relación con un padre débil e indeciso, y que el papel de joven desorientado de Platón se explica por el abandono de sus padres. Sobre el mismo filme, Robert Landry (1955) ubica como centro de la trama al comportamiento rebelde de Jimmy hacia sus padres. Igual que hace el propio guionista, Landry llama la atención sobre estos últimos. Al padre lo describe como un hombre carente de fuerza y a la madre como una mujer malhumorada. Así como lo hicieron ambos críticos de cine, es muy probable que los estadounidenses de la época también se percataran de las cuestiones familiares que atravesaban la trama de los filmes y que las consideraran centrales. No en vano, las interpretaciones de algunos académicos de la época sobre la causa de la rebeldía apuntaban a la ausencia paterna (Parsons, 1967; Goodman, 1971; Riesman, 1971), ausencia que se correlacionaba con hechos empíricos como la menor permanencia de los padres en los hogares debido a las largas distancias entre estos últimos y sus lugares de trabajo. Fenómeno que se intensificó con la migración de parte de la clase media a los suburbios y con los recuerdos de una Segunda Guerra Mundial durante la cual las familias fueron separadas (Brinkley, 1966).

No solo la desobediencia explicita de las normas paternas por parte de los jóvenes fue motivo de conflicto familiar. También lo fue la falta de comprensión entre padres e hijos. Rebel Without a Cause inicia con unos padres preocupados por su hijo, que acuden a una autoridad mayor, el Sargento. Este parece tener mejor dominio frente al comportamiento del joven rebelde y termina asumiendo un rol paternal frente a aquel. Los padres no comprenden el porqué del comportamiento de Jimmy, y él no se siente comprendido por ellos. Así lo da entender la narración con fragmentos como el siguiente, en el que Jimmy, gritando entre lágrimas, les reprocha a sus padres: 


\section{DISERTACIONES}

ENSAYOS

Estudios sobre imágenes en el nuevo ecosistema mediático

ISSN: $1856-9536$

Doi: https://doi.org/10.12804/revistas.urosario.edu.co/disertaciones/a.7934

Volumen 13, Número 2 / Julio-diciembre 2020

Versión PDF para imprimir desde

http://revistas.urosario.edu.co/index.php/disertaciones

“¡Me están destrozando! Tú dices una cosa, él dice otra, y después cambian de idea” (Ray, 1955). En Blackboard Jungle retratan la impotencia por parte de los adultos para lidiar con los nuevos jóvenes, esta vez bajo los roles de maestro y estudiante. En East of Eden, película del mismo año, se hallan aspectos similares. Adam, padre de Aron y Cal, habla sobre este último con Will, un futuro socio.

Will: "Vamos Adam, solo es un poco irreflexivo"

Adam: "¿Irreflexivo? Es un desconsiderado. Ese chico ha agotado mi paciencia. No lo comprendo, nunca lo he comprendido" (Kazan, East of Eden, 1955).

Las brechas que se interponen en la comunicación parecen tener una base empírica y no ser un producto propio de la industria cinematográfica. David Riesman (1971) alertó sobre cómo el lenguaje de un grupo de edad específico, trasmitido dentro de un grupo de pares, se puede tornar incomprensible para un observador marginal. Además, plantea que el niño recibe mensajes distantes al círculo de comunicación que mantenía con sus padres, experimentando un mundo mucho más extenso que el familiar. De una u otra forma, esto implicó una pérdida de control por parte de los padres, considerando que se redujo su incidencia en la socialización y se abrieron distancias comunicativas entre ambos grupos de edad, mientras que aumentaba la influencia del grupo de pares de los jóvenes. Un menor control sobre la socialización de los hijos pudo haber devenido en mayor incertidumbre.

La manera en que la rebeldía es descrita por los críticos de cine, más allá de ser indicio del miedo que suscitó, plantea una relación, explicita en ocasiones, entre esta y el entorno familiar, sobre el cual, como se mencionó más arriba, se percibían múltiples amenazas. Pero no solo la rebeldía minó en la familia en tanto desafío a la autoridad. Los filmes citados manifiestan una discrepancia entre los deseos y preocupaciones de ambos grupos de edad, que se expresan en esfuerzos vanos emprendidos por los adultos encaminados a modificar la conducta de los jóvenes. Si esto se correlaciona con los análisis académicos citados, se puede pensar que las dificultades de comprensión entre padres e hijos fueron un verdadero problema en el mundo empírico, que fue luego proyectado en la gran pantalla. Tanto rebeldía como incomprensión se traducen en potencial pérdida de control por parte de los padres, situación más alarmante para los adultos que para los adolescentes.

\section{El protestantismo a la luz del rebelde}

\section{La intensificación del ímpetu religioso como reacción ante la angustia}

En su análisis de los valores estadounidenses, Seymour Lipset (1966) identifica la ética protestante como una fuente central, habiendo esta conducido a la búsqueda de realización personal, prosperidad y éxito. Para Lipset, las bases morales del país, entre los que destacan los valores religiosos, han mantenido continuidad, a pesar de las variaciones en materia de economía o demografía que ha sufrido. Pero, ¿qué causas pudieron haber dirigido, y quizá intensificado, las motivaciones religiosas, particularmente protestantes, hacia los jóvenes a mediados del siglo xx?

1 Paul Goodman ve inconveniente para la salud mental de los niños que los padres no logren estar de acuerdo dentro del hogar (Goodman, 1971). Opinión seguramente compartida por muchos estadounidenses. 


\section{DISERTACIONES}

ENSAYOS

Estudios sobre imágenes en el nuevo ecosistema mediático

ISSN: $1856-9536$

Doi: https://doi.org/10.12804/revistas.urosario.edu.co/disertaciones/a.7934

Volumen 13, Número 2 / Julio-diciembre 2020

Versión PDF para imprimir desde

http://revistas.urosario.edu.co/index.php/disertaciones

Estados Unidos, dice Castells (2001), se caracteriza por un alto dinamismo en cuanto a cambio social, motivo que promueve a la población a que busque refugio en las instituciones tradicionales y los credos que sostienen una verdad eterna, para así hallar un espacio de tranquilidad en medio de la embestida de la modernidad. El siguiente fragmento del autor, pese a hacer referencia a la década de 1980, puede ser ilustrativo:

[...] mientras que la amenaza comunista proporcionó una base para que se estableciera la identificación entre los intereses del gobierno estadounidense, el cristianismo y los Estados Unidos como la nación elegida, el derrumbamiento de la Unión Soviética y el surgimiento de un nuevo orden global crearon una incertidumbre amenazadora sobre el control del destino de los Estados Unidos (Castells, 2001, p. 48).

La amenaza comunista de la que habla Castells estaba a flor de piel en la década de 1950. Desde una posición moral, propia de unos fervorosos cristianos que repudiaban el comunismo (o comunismo ateo, como lo llamó Eisenhower en un discurso), el presidente Eisenhower y John Dulles, su mano derecha, consiguieron imprimirle a la Guerra Fría el carácter de una guerra santa, como se evidencia en este fragmento del discurso de posesión de Eisenhower, citado por Fontana (2011): "las fuerzas del bien y el mal están reunidas, armadas y enfrentadas como pocas veces antes en la historia” (p. 203). El ambiente de incertidumbre que derivó del miedo a la Guerra Fría y la interpretación moral con que la revistió el gobierno debieron aumentar la angustia y, a su vez, las presunciones de los Estados Unidos, resaltadas por Galtung (1999), de auto-reconocerse como país representante de Dios en la tierra.

Uno de los componentes importantes del fundamentalismo cristiano estadounidense dentro del análisis de Castells (2001) es su búsqueda de identidad en imágenes y aspectos del pasado que puedan ser reivindicados en el presente y proyectados como futuro ideal. Para Daniel Bell (1992), la sociedad de masas, por su interconexión y multiplicación de estímulos, acelera tanto el dinamismo social, que dificulta la capacidad de absorción de información por parte de los individuos. Como reacción, la sociedad misma se orienta hacia las instituciones que preservan el pasado, con el fin de hallar resguardo frente a los cambios que confunden y desestabilizan a sus miembros. Dentro de estas instituciones, la familia, la iglesia y la escuela ocupan un lugar privilegiado. Este giro hacia las tradiciones y el deseo de conservar las formas institucionales de antaño, como reflejo ante la angustia e incertidumbre, incidió en los contenidos de las películas aquí analizadas.

\section{El protestantismo reviste al joven rebelde}

Cuando las imágenes de la película coinciden con las imágenes interiores del sujeto, que implican gran familiaridad, este halla satisfacción (Metz, 1979). Tal parece ser lo que ocurre con la imagen del joven rebelde en el cine. Por un lado, se sitúa en un lugar central al objeto que en el mundo empírico aparece como causante de preocupación: el adolescente. Por otro lado, se le reviste en la representación con algunos de los valores y comportamientos que por ese entonces parecían estar amenazados, varios de ellos propios del protestantismo, como se mostrará a continuación.

Mediante este proceso se construye una imagen traducida a códigos familiares que los adultos, y la población en general, pueden asimilar como algo cercano. De esta manera, es probable que la brecha entre códigos comunicativos tratada más arriba se difumine dentro de la pantalla, aquel aparato simbólico que materializa lo imaginario. 


\section{DISERTACIONES}

ENSAYOS

Estudios sobre imágenes en el nuevo ecosistema mediático

ISSN: $1856-9536$

Doi: https://doi.org/10.12804/revistas.urosario.edu.co/disertaciones/a.7934

Volumen 13, Número 2 / Julio-diciembre 2020

Versión PDF para imprimir desde

http://revistas.urosario.edu.co/index.php/disertaciones

El joven rebelde no aparece en la gran pantalla luego de la ocurrencia de un director que construyó su imagen. Fue, por el contrario, el producto de las mediaciones con el mundo empírico, que en su tránsito al plano de la representación se impregnó de los valores de quienes se encargaron de hacerlo. La preocupación religiosa por mantener una moral en aras del bienestar de su pueblo puede dirigir su atención hacia los medios masivos de comunicación, no tanto como estrategia fijada mediante una racionalidad instrumental, sino como manifestación no consciente de contenidos arraigados a la población estadounidense.

\section{El joven rebelde a solas con Dios}

Películas como Rebel Without a Cause (1955), East of Eden (1955), Somebody Up There Likes Me (1956) o Giant (1956) tienen en común a un joven rebelde que se muestra aislado del resto de la sociedad. Mientras que el vaquero o el sheriff, héroes de la cultura estadounidense (Lipset, 1993), ostentan ocupaciones que les delegan legitimidad y prestigio, los rebeldes se encuentran más abajo en la jerarquía social. No cuentan con personas subordinadas a sus órdenes, no representan figuras de autoridad ni suelen ejercer ningún oficio lucrativo. En dado caso de que se les represente en un trabajo, es uno en el que deben obedecer a sus superiores y en el cual solo llevan a cabo labores manuales propias de los obreros. Sus vínculos de amistad son muy escasos, si no inexistentes. Ni en el trabajo, ni en la escuela, ni dentro de su familia mantienen interacciones íntimas y constantes. Su actitud hacia el mundo y las características de su entorno los conducen al aislamiento, no como el héroe que emprende solo el camino con un público a sus espaldas que lo admira, sino como un joven confundido con problemas para entablar relaciones y sin deseos de hacerlo, que suele encontrar sanción social en sus acciones.

Ninguno de los jóvenes rebeldes parece necesitar de los otros, no porque gocen de cualidades que los hagan superiores a ellos, como podría ser el caso de personajes icónicos de la cultura estadounidense como James Bond, sino porque identifican el origen de sus problemas en su propia interioridad. Aquí puede detectarse un primer símil con el tipo-ideal del protestante, que procuró abandonar a los mediadores que le ofrecían apoyo al contactarlo con Dios y optó, en cambio, por encontrarlo él mismo en un dialogo directo.

John Conway, citado por Lipset (1993), afirma que el protestantismo que penetra entre los valores generales de los Estados Unidos tiene como base la noción del individuo a solas con Dios. Harold Bloom (1997) da con los fundamentos de lo que llama la 'religión estadounidense', una con características únicas del país que no pueden ser reducidas a ninguna religión en particular. Allí identifica rasgos que considera centrales y que están, según afirma, presentes en todo estadounidense, como lo es la identidad entre la libertad y el estar a solas con Dios, idea metafísica que se concretiza en la mucho menos abstracta noción de soledad. Esto parece concordar con lo que se ha dicho del joven rebelde.

East of Eden (1955) muestra una conversación entre Aron, hermano de Cal, y su novia, Abra. En esta se expresa la curiosidad e inseguridad que despierta Cal en aquellos cuya conducta es considerada normal:

Abra: No le cae bien nadie, ¿verdad? ¿Por qué está siempre solo?

Aron: porque quiere...

Abra: Nadie quiere estar siempre solo [...] da miedo [...] cuando te mira, como un animal. No sé, a mí me da miedo (Kazan, 1955). 


\section{DISERTACIONES}

ENSAYOS

Estudios sobre imágenes en el nuevo ecosistema mediático

ISSN: $1856-9536$

Doi: https://doi.org/10.12804/revistas.urosario.edu.co/disertaciones/a.7934

Volumen 13, Número 2 / Julio-diciembre 2020

Versión PDF para imprimir desde

http://revistas.urosario.edu.co/index.php/disertaciones

La soledad en estas películas está narrada de forma tal que comunica la existencia de un contraste entre el rebelde y el resto de la población, funcionando como estrategia para individualizar al primero: mostrarlo con características que lo diferencien de los demás para que así resalte su individualidad.

Jimmy es un joven sin amigos a quien su padre, preocupado por su primer día en la nueva escuela, alienta diciéndole: "joven, que queden con la boca abierta como pasaba con tu padre [...] Cuidado cómo eliges a tus amigos. ¿Sabes a qué me refiero? Que no te elijan a ti”. De personalidad hermética, Jimmy destaca por su soledad y sus pocas interacciones sociales (Ray, 1955). Jett, igualmente hermético, presencia a distancia una emotiva fiesta, mostrando completo desinterés en hacer parte de las interacciones que allí se desenvuelven. Mientras tanto, aguarda solitario en un carro, actitud que repite varias veces en el filme y que será característica de su personaje (Stevens, 1956). Todas las escenas tienen en común, además de ser interpretadas por el mismo actor (James Dean), que quieren poner un énfasis en la soledad del rebelde, fuertemente emparentada con su actitud frente al mundo en general.

\section{Auto-cuestionamiento moral y auto-observación}

En sí mismo, el asilamiento no dice mucho. Lo que le confiere una carga significativa es que se le represente como recurso de quien tiene problemas que provienen de su interior, referentes a temas como la identidad o relacionados con dilemas morales de gran profundidad, atravesados por una incomprensión por parte de los demás. Riesman (1971) dice del niño protestante que en su proceso de crecimiento va aprendiendo a auto-observarse, adquiriendo un alto sentido de la responsabilidad consigo mismo, asignándole, por ende, gran importancia a la terea de vigilar si están cumpliendo con los imperativos que arrastran sus ideales. Uno de ellos es el de "ser bueno", demanda que los impulsa a adoptar un constante cuestionamiento propio, relacionado con el estar a solas. En las películas se rastrean fragmentos en los que se representan juicios morales provenientes del exterior, dirigidos a los rebeldes, en los que se los tacha de malos o en los que se cuestiona su moralidad. Aquellas etiquetas suelen provenir de figuras de autoridad y en la totalidad de los casos son enunciados por adultos. El padre de Barbella le grita a su hijo: "te miro y veo al diablo" (Wise, 1956). O el jefe de policía le dice a Johnny: "no sé si hay algo bueno en ti, no sé si hay algo en ti, pero voy a correr el gran riesgo y dejar que te vayas" (Benedek, 1953). Pero, pese a estos u otros ejemplos, son los juicios contra sí mismos los que desempeñan una función más relevante en las películas.

El personaje de Cal ejemplifica la angustia nacida de la división cristiana entre el bien y el mal. Observando una fotografía de sus padres, dice en referencia a su madre: "ella no es buena y yo tampoco. Sabía que había alguna razón por la que yo no era bueno. La odio, y a él también". En otra escena, mientras conversa con su padre luego de haberlo enfadado con su comportamiento retador y altanero, este le grita a Cal: "¿¿no te arrepientes!? ¡Eres malo!, malo de pies a cabeza”. Cal responde: "tienes razón, soy malo. Hace tiempo que lo sabía”, y agrega: "Aron es el bueno. Supongo que recibes cierta cantidad de bueno y de malo de tus padres y yo solo recibí lo malo" (Kazan, 1955). Por como indican los diálogos, Cal no necesita de un juicio externo para conocer lo que para él está claro, su condición de maldad. Por el contrario, la narración da a entender que es una carga de la que era consciente y la cual lleva arrastrando. Para Harold Bloom (1997), el espíritu consciente de sí mismo es un estado propio del estadounidense, en estrecha relación con el significado que se le otorga a la soledad. El estadouni- 


\section{DISERTACIONES}

ENSAYOS

Estudios sobre imágenes en el nuevo ecosistema mediático

ISSN: $1856-9536$

Doi: https://doi.org/10.12804/revistas.urosario.edu.co/disertaciones/a.7934

Volumen 13, Número 2 / Julio-diciembre 2020

Versión PDF para imprimir desde

http://revistas.urosario.edu.co/index.php/disertaciones

dense heredó del protestantismo la convicción de que el individuo debe confrontarse a sí mismo, y no esperar la ayuda de su comunidad o de su secta, para encontrar la salvación (Bloom, 1997). Seymour Lipset (1993) agrega que, como consecuencia de la ética protestante que predomina en el país, los estadounidenses están orientados a seguir la voz de su conciencia, por encima incluso de instituciones como el Estado. De ahí la importancia del auto-reconocimiento y la preocupación por la identidad, que se expresa en algunos fragmentos donde a los jóvenes en general, y no solo a los rebeldes, se les representa confundidos respecto a su moralidad, como lo evidencia una frase de Abra mientras conversa con Cal: "a veces creo que soy mala de verdad. Otras veces no sé qué pensar... no pienso que yo sea mala de verdad" (Kazan, 1955), la frase que pronuncia Jimmy cuando dialoga con sus padres con signos de gran afección: "Nunca hice nada bien, llevo años con líos en la cabeza" (Ray, 1955) o las palabras que Barbella intercambia con su madre:

Madre: no te están buscando. La policía vino antes a decirme que el hermano Benedict te ha dado por

perdido. Ya no te quieren en el internado. Han dicho que no vuelvas.

Barbella: no valgo para nada, todos los saben (Wise, 1956).

Lo que aporta mayor significado a los cuestionamientos del rebelde sobre su posición dentro de la maniquea división entre bien y mal es, por un lado, su aislamiento en gran medida voluntario y, por otro, su individualismo y el valor que le presta a la voz de su conciencia. En las películas en las que el joven rebelde funge como protagonista, es representado como terco y obstinado, fiel a las demandas de su interior. En la narración, suelen ser las decisiones guiadas por este patrón de conducta las que desencadenan los puntos de giro que dinamizan el relato. Características fácilmente atribuibles a un joven, la obstinación y la terquedad son cualidades coherentes con la actitud protestante de escuchar la voz de la conciencia por encima de cualquier otra, de manera que podrían ser un recurso utilizado de forma inconsciente para cristianizar la representación sin distorsionar dramáticamente su correlato empírico: el joven de carne y hueso con comportamientos desviados. La terquedad y la obstinación son, además, afines con una actitud eficaz para la realización personal que viene con la consecución de metas.

Hay elementos narrativos que le confieren al joven rebelde la total responsabilidad de sus actos que, como afirmó Parsons (1968), es una consecuencia con la que debe lidiar el protestante por haberse desvinculado de cualquier mediador en aras de una comunicación directa con Dios. Barbella, en su estancia en la cárcel, tras cometer diferentes acciones desviadas, escucha a su madre en el horario de visita: "Rocky, tú eres quien me hace pasar las noches preocupada sin poder dormir. Volviéndome loca". Su madre continúa: "hablé con él [refiriéndose al cura] y me dijo que estaba haciendo lo correcto. Dijo que nadie puede ayudarte Rocky, solo tú mismo. Eso me dijo el cura" (Wise, 1956). Jimmy tiene claridad de que solo acatar su conciencia, aun en contra de lo que le sugiere la autoridad paternal, es el único medio para alcanzar la tranquilidad espiritual, por eso dice mientras discute con sus padres sobre la muerte de otro joven en la que, de alguna forma, estuvo involucrado: "iré a la policía a decirles que estoy involucrado". Los padres explicitan su desacuerdo. El padre, mucho menos imperativo que la madre, le dice "está lejos de mí decirte qué hacer". El padre continúa: "nadie te agradece porque pongas la cabeza”, a lo que Jimmy responde "excepto uno mismo... excepto uno mismo" y agrega: "¡Mamá, se mató un chico esta noche. No puedo salir de esto haciendo de cuenta que no sucedió!" (Ray, 1955). La voz de su conciencia, como evidencia el fragmento, ejerce mayor peso que la misma autoridad paterna. 


\section{DISERTACIONES}

ENSAYOS

Estudios sobre imágenes en el nuevo ecosistema mediático

ISSN: $1856-9536$

Doi: https://doi.org/10.12804/revistas.urosario.edu.co/disertaciones/a.7934

Volumen 13, Número 2 / Julio-diciembre 2020

Versión PDF para imprimir desde

http://revistas.urosario.edu.co/index.php/disertaciones

\section{Ocio y trabajo, dos caras morales del joven rebelde}

Como es de esperar de los productos que tienen el sello de Hollywood, al final los dilemas morales de los jóvenes rebeldes quedan narrativamente resueltos. Los vuelcos morales que toma cada narración van en sintonía con una industria cinematográfica en cuyas historias siempre triunfa el bien. Pero no todas las representaciones del rebelde tienen este destino. Las películas definen, sin puntos intermedios, quiénes tomaron el camino del "bien" y quiénes el del "mal", y ligado a cada uno hay, respectivamente, un destino de triunfo y uno de fracaso. La pregunta que aquí interesa es qué aspectos de la conducta se asocian con cada oposición moral y qué cambios en los personajes generan, bien un estado de gracias o bien un deterioro moral.

Algunos importantes signos de moralidad se hallan entre la dicotomía trabajo arduo y ocio. El protestantismo le asigna elevada importancia al trabajo como ruta hacia la realización. En el clásico texto de Max Weber, La Ética Protestante y el Espíritu del Capitalismo, se muestra con claridad esta idea. El éxito laboral y, en consecuencia, económico era interpretado por los protestantes como evidencia de que Dios los había recubierto con su gracia, abriéndoles las puertas a la salvación. De esta forma, el trabajo y la vida religiosa se hermanaron en la ética protestante. El imperativo que yacía sobre quienes la interiorizaron hizo del logro personal, expresado comúnmente en éxito económico, una cuestión fundamental. Seymour Lipset (1966) anota que esta característica del protestantismo estadounidense pesó mucho sobre sus fieles, preocupados por hallar la realización mediante logros individuales.

El trabajo individual, más que las ocupaciones que implican la actividad conjunta de varios individuos, es el ideal para la realización de los protestantes, según apunta Parsons (1968). Parece ser la disposición de algunos de los jóvenes rebeldes representados, especialmente cuando están motivados por buenas intenciones. Un claro ejemplo lo brinda Cal cuando decide colaborarle a su padre en su negocio de venta de hielo. El joven muestra gran esmero en esta empresa, motivado no por el dinero en sí mismo, sino por el logro. Luego del fracaso con el hielo, Cal emprende un proyecto personal: recuperar el dinero invertido por su padre. Para ello, continúa con sus laboriosos horarios de trabajo, ahora en el negocio del cultivo de porotos, el cual culmina con gran éxito. Es destacable que se le represente como un proyecto que lleva a cabo individualmente y con el máximo grado de compromiso.

Los trabajos realizados por los jóvenes rebeldes son de carácter individual y en ellos recae toda la responsabilidad de las consecuencias. No se les representa como empleados de una fábrica, desempeñando una función que se oculta en medio del trabajo de una fila de individuos. Por el contrario, son trabajos como el de Barbella y Jett. Respectivamente, un boxeador, cuyo éxito y fracaso depende de sus habilidades individuales, y un ayudante de una hacienda que hace su labor en solitario. Ambos guardan la idea de alcanzar la realización por medio del logro personal. Barbella, por ejemplo, es alcanzado por las palabras de su madre mientras sale afanado de su casa. Ella le pregunta "¿a dónde vas?", a lo que él responde "a ser alguien" (Wise, 1956). Igual de claro es el caso de Jett, una representación del hombre trabajador que forja su propio destino gracias a su esfuerzo. Luego de heredar una porción de tierra, se le muestra en constante actividad, dedicado a levantar su casa. Su empeño continúa una vez halla petróleo en suelo de su propiedad, logrando erigir, sin mayor ayuda, unas torres para la extracción del 


\section{DISERTACIONES}

ENSAYOS

Estudios sobre imágenes en el nuevo ecosistema mediático

ISSN: $1856-9536$

Doi: https://doi.org/10.12804/revistas.urosario.edu.co/disertaciones/a.7934

Volumen 13, Número 2 / Julio-diciembre 2020

Versión PDF para imprimir desde

http://revistas.urosario.edu.co/index.php/disertaciones

hidrocarburo. Su imagen se asemeja a la del colono que se asienta en nuevas tierras y hace de ellas un centro de desarrollos e innovaciones.

En el protestantismo no todo éxito económico es bien visto. Cuando el fin de la actividad de un individuo es la riqueza, dice Weber (2001), se cae en la codicia, inclinación rechazada de forma tajante por el protestantismo. Incluso puede ser señal de deterioro moral, como se muestra en la versión adulta de Jett, en la que se encamina a una vida de despilfarros, excentricidades y consumo excesivo de alcohol, contaminado por la soberbia. Durante esta etapa de la representación, exhibe con orgullo sus bienes materiales, con aires de superioridad. Cumple así con la mayor parte de las condiciones para ser rechazado por la ética económica del protestantismo, como se evidencia en esta frase de Weber (2001, p- 209): "el ascetismo odia por igual tanto la elegante despreocupación del señor como la ostentación del nuevo rico". En una frase de Weber:

[...] lo realmente reprochable desde el punto de vista moral es recrearse en la riqueza, disfrutar de la riqueza con sus consecuencias de ocio y molicie y, sobre todo, con la consecuencia de desviarse de la aspiración a la vida santa (Weber, 2001, pp. 196-197).

Para Riesman (1971), los protestantes tienen una relación particular con el tiempo libre, pues rechazan la idea de desperdiciarlo. En consecuencia, el tiempo que dedican al ocio es escaso, a no ser que la actividad les provea alguna mejora personal que la justifique. El ocio, además, fue asociado durante la época con poblaciones estigmatizadas como los jóvenes Beat (Goodman, 1971). No es aleatorio que a los jóvenes rebeldes, generalmente personajes secundarios, a quienes se les representa, no realizando ninguna actividad encaminada al logro económico que resulte del trabajo honrado, sino en estado de reposo o en actividades de ocio "inmoral", asuman un papel antagónico y sean castigados por la sociedad.

\section{Conclusiones}

La rebeldía juvenil despertó la preocupación de los estadounidenses a mediados del siglo xx. Seguramente fueron los padres los más alarmados, al ver cómo se ponía en riesgo su autoridad y control sobre sus hijos. De una parte, por los problemas de comunicación y la consecuente incomprensión entre adultos y jóvenes y, de otra, por la desobediencia explícita a las normas. Ambos problemas representados en las películas como reflejo de lo que se vivía, o se percibía, en los hogares estadounidenses. Es probable que la angustia derivada de estos problemas familiares se intensificara a raíz del miedo hacia el enemigo interno, el deterioro moral, la ausencia paterna en los hogares, las manifestaciones contraculturales o las pandillas juveniles, entre otros factores.

Pero no solo la preocupación por el bienestar moral de las nuevas generaciones las situó como centro de atención. La individualización de los hijos y la idealización de la familia y de la juventud fueron factores que cumplieron también un papel clave, fomentando el deseo de la población de imitar a sus jóvenes y hacerlos portadores de sus expectativas e ilusiones.

En una estructura valorativa como la estadounidense, un ataque contra la moral o la familia tradicionales implica, directa o indirectamente, un ataque contra la ética protestante. O por lo menos así se percibía. Pero esta misma amenaza pudo haber exacerbado el ímpetu religioso de los estadounidenses y su deseo de preservar sus valores e instituciones más representativos. 


\section{DISERTACIONES}

ENSAYOS

Estudios sobre imágenes en el nuevo ecosistema mediático

ISSN: $1856-9536$

Doi: https://doi.org/10.12804/revistas.urosario.edu.co/disertaciones/a.7934

Volumen 13, Número 2 / Julio-diciembre 2020

Versión PDF para imprimir desde

http://revistas.urosario.edu.co/index.php/disertaciones

Las instituciones que cumplen una función paterna de cuidado y transmisión de valores, particularmente la familia, fueron protagónicas en la construcción de la imagen del joven rebelde. Al considerar la estructura de valores estadounidense, no sorprende que en las películas la familia sea responsabilizada por las desviaciones juveniles, representando a padres carentes de fortaleza y determinación o hundidos en el alcoholismo, y a padres y madres desentendidos del cuidado familiar o ausentes. Por estas y otras características de los filmes, se puede plantear a modo de hipótesis que el cine del joven rebelde obró como fuente de desahogo de angustias de la sociedad.

En ese orden de ideas, también se puede pensar que fue un espacio de expresión de deseos colectivos. Por eso algunos jóvenes rebeldes fueron revestidos con valores y conductas apreciadas por el grueso de los estadounidenses y fueron traducidos a códigos familiares que los adultos, y la población en general, pudieron asimilar como cercanos. Entre dichos valores destaca el influjo protestante: la soledad reflexiva y el aislamiento, compatible con el modelo de estar a solas con Dios, así como la preocupación moral por la interioridad: la inclinación a seguir la voz de la propia conciencia por encima de cualquier autoridad; o la dicotomía entre jóvenes laboriosos motivados por la realización personal y aquellos que caen en la codicia o bien se encaminan al ocio o a actividades lucrativas desviadas. Así, pues, el joven rebelde de Hollywood pudo no solo haber sido reflejo del grito de emancipación adolescente, como plantearon varios autores, sino, más bien, una imagen moldeada por los valores protestantes y un reflejo de una población adulta temerosa.

\section{Referencias}

1. Bell, D. (1992). Modernidad y sociedad de masas: variedad de las experiencias culturales. En D. Bell, Industria Cultural y Sociedad de Masas. Caracas: Monte Ávila Editores.

2. Benedek, L. (Dirección). (1953). The Wild One [Película]. Estados Unidos: Stanley Kramer Pictures Corp.

3. Bloom, H. (1997). La religión en los Estados Unidos: el surgimiento de la nación poscristiana. México: Fondo de Cultura Económica.

4. Brinkley, A. (1996). Historia de Estados Unidos. México: McGraw-Hill.

5. Brooks, R. (Dirección). (1955). Blackboard Jungle [Película]. Estados Unidos: Metro-Goldwyn-Mayer.

6. Castells, M. (2001). La Era de la Información. El poder de la identidad. Buenos Aires: Siglo xxı.

7. Crowther, B. (31 de diciembre de 1953). Two Films in Bow Here; ' The Wild One,' Starring Marlon Brando as a Motorcyclist, Is on View at Palace 'Paratrooper,' With Alan Ladd as a Lone Wolf, Opens at Criterion -- Young Directs. The New York Times. Recuperado de http://www.nytimes.com/movie/ review?res=9B03E7DC123EE53BBC4950DFB4678388649EDE

8. Crowther, B. (27 de octubre de 1955). The Screen: Delinquency; ' Rebel Without Cause' Has Debut at Astor. The New York Times. Recuperado de http://www.nytimes.com/movie/review?res=9F02E0DB1 F3AEF34BC4F51DFB667838E649EDE

9. Crowther, B. (10 de marzo de 1955). The Screen: 'East of Eden' Has Debut; Astor Shows Film of Steinbeck Novel. The New York Times. Recuperado de http://www.nytimes.com/movie/review?res=9C0DEFD 6143EE53ABC4852DFB566838E649EDE 


\section{DISERTACIONES}

ENSAYOS

Estudios sobre imágenes en el nuevo ecosistema mediático

ISSN: $1856-9536$

Doi: https://doi.org/10.12804/revistas.urosario.edu.co/disertaciones/a.7934

Volumen 13, Número 2 / Julio-diciembre 2020

Versión PDF para imprimir desde

http://revistas.urosario.edu.co/index.php/disertaciones

10. Crowther, B. (21 de marzo de 1955). The Screen; 'Blackboard Jungle'; Delinquency Shown in Powerful Film. Recuperado. Recuperado de http://www.nytimes.com/movie/review?res=9803E1DE153EE53 ABC4951DFB566838E649EDE

11. Crowther, B. (6 de Julio de 1956). The Screen: Hate Worked for Him; Graziano Fight Story Is Shown at State Paul Newman Stars as Ring Champion. The New York Times. Recuperado de http://www.nytimes.com/ movie/review?res=9E0DE3D91E3EE333A05755C0A9619C946792D6CF

12. Dinerstein, J., \& Goodyear, F. (2014). American cool. Washington, D.C.: Delmonico Books- Prestel.

13. Ferro, M. (1980). Cine e Historia. Barcelona: Gustavo Gili.

14. Fontana, J. (2011). Por el bien del imperio: una historia del mundo desde 1945. Barcelona: Ediciones de Pasado y Presente.

15. Galtung, J. (1999). Fundamentalismo USA. Barcelona: Icaria.

16. Gonzáles-Anleo, J. M. (2014). Consumidores consumidos. Juventud y cultura consumista. Madrid: Khaf.

17. Goodman, P. (1971). Problemas de la juventud en la sociedad organizada. Barcelona: Península.

18. Hareven, T. (1990). Continuidad y cambio en la familia estadounidense. En L. Luedtke, La creación de los Estados Unidos: la sociedad y la cultura de los Estados Unidos (pp. 241-253). Washington: Servicio Cultural e Informativo de los Estados Unidos.

19. Huddleston, D. (2012). The Beat Generation: They Were Hipsters Not Beatniks. EEUU: Western Oregon University.

20. Kazan, E. (Dirección). (1955). East of Eden [Película]. Estados Unidos: Warner Bros.

21. Landry, R. (26 de octubre de 1955). Rebel Without a Cause. Variety. Recuperado de http://variety.com/1955/ film/reviews/rebel-without-a-cause-1200417958/

22. Lipovetsky, G., \& Serroy, J. (2009). La pantalla global. Cultura mediática y cine en la era hipermoderna. Barcelona: Anagrama.

23. Lipset, S. M. (1966). Estados Unidos: Juicio y análisis. Cali: Norma.

24. Lipset, S. M. (1993). La división continental: los valores y las instituciones de los Estados Unidos y Canadá. México, D.F.: Fondo de Cultura Económica.

25. Martín-Barbero, J. (2010). De los medios a las mediaciones: comunicación, cultura y hegemonía. Barcelona: Anthropos.

26. Metz, C. (1979). Psicoanálisis y cine. El significante imaginario. Barcelona: Gustabo Gili.

27. Morin, E. (1964). Las estrellas del cine. Buenos Aires: EUDEBA.

28. Morin, E. (1966). El espíritu del tiempo. Madrid: TAURUS.

29. Parsons, T. (1967). Ensayos de teoría sociológica. Buenos Aires: Paidós.

30. Parsons, T. (1968). La estructura de la acción social: estudio de teoría social con referencias a un grupo de recientes escritores europeos. Madrid: Guadarrama.

31. Ray, N. (Dirección). (1955). Rebel Without a Cause [Película]. Estados Unidos: Warner Bros. Pictures.

32. Riesman, D. (1971). La muchedumbre solitaria. Barcelona: Paidós.

33. Rubio Lapaz, J., \& Kanelliadou, V. (2009). Las imágenes de la contracultura y su apropiación neocapitalista como apariencia. La rebeldía como valor de consumo. Recuperado de https://digitum.um.es/digitum/bitstream/10201/44448/1/Congresolmagen145.pdf 


\section{DISERTACIONES}

\section{ENSAYOS}

34. Sadoul, G. (1989). Historia del cine mundial: desde los orígenes hasta nuestros días. México: Siglo Veintiuno.

35. Stevens, G. (Dirección). (1956). Giant [Película]. Estados Unidos: George Stevens Productions.

36. Stevens, R. (Dirección). (1958). Never Love A Stranger [Película].

37. Turner, A. (1987). Hollywood: años 50. Barcelona: Arín. Estados Unidos: Allied Artists Pictures.

38. Variety Staff. (31 de diciembre de 1952). The Wild One. Variety.

39. Variety Staff. (31 de diciembre de 1955). Somebody Up There Likes Me. Variety. Recuperado de http:// variety.com/1955/film/reviews/somebody-up-there-likes-me-2-1200418035/

40. Weber, M. (2001). La Ética protestante y el Espíritu del Capitalismo. Madrid: Alianza Editorial.

41. Wise, R. (Dirección). (1956). Somebody Up There Likes Me [Película]. Estados Unidos: Metro-Goldwyn-Mayer. 